\title{
Detection of Extended Spectrum Beta-Lactamases from a Pet Blue-Fronted-Amazon Parrot (Amazona aestiva)
}

\author{
Karoline Franciani Cardoso Lopes', Rodrigo Assunção Moura', Ricardo de Melo Germano', \\ José Ricardo Pachaly', Isabela Carvalho dos Santos', Lisiane de Almeida Martins', \\ Marco Aurélio Cunha Del Vechio² \& Daniela Dib Gonçalves'
}

\begin{abstract}
Background: The indiscriminate use of antibiotics both in humans and in animals, has contributed to the development of bacterial resistance. One of the key mechanisms in the resistance of enterobacteria to antibiotics is the production of extendedspectrum $\beta$-lactamases (ESBLs), which reduce the therapeutic options available. Several studies have been performed in different animal species in order to isolate and identify multidrug-resistant strains and determine their antibiotic sensitivity profile. The purpose of this study was to detect ESBL-producing enterobacteria in isolates from a pet blue-fronted amazon parrot. Case: A 16-year-old pet blue-fronted-amazon parrot (Amazona aestiva) weighing $0.445 \mathrm{~kg}$, from the city of Presidente Castelo Branco, Paraná, Brazil, was admitted into a specialized veterinary clinic in the city of Maringá. This parrot was presented with agitation and aggressive behavior. It was fed with sunflower seeds, and its cage was small and unsanitary especially in the feeding and drinking areas, which were heavily contaminated with feces. The parrot had been diagnosed with acute sinusitis approximately one year prior, with a history of treatment with tylosin, thuya (a herbal remedy popularly used for fowl pox), and a mineral-vitamin complex. The clinical symptoms included dyspnea and bilateral increase of facial swelling, with a mass in the peri-nasal region. A membranous red tissue not related to the nictitating membrane was observed in the lower left eyelid. To obtain a better clinical evaluation, the bird was anesthetized with an intramuscular injection of dextroketamine $50 \mathrm{mg} / \mathrm{kg}$ (KetaminS+ ${ }^{\mathrm{TM}}$ ). Subsequently, physical examination, head radiographic examinations, and an attempt at sinus draining were performed. The radiographic examinations showed a decreased amount of air in the nasal sinuses. For treatment, oral itraconazole and vitamin A were prescribed, and a dietary improvement, prioritizing the offering of fruits and industrialized food for parrots was proposed. Samples were collected from the cloaca and choanae by making rotating movements with compressed sterile swabs in the corresponding locations. All samples were kept in Amies transport media with activated coal and forwarded under refrigeration to the Laboratory of Preventive Veterinary Medicine and Public Health in the Post-Graduation Program in Animal Sciences with Emphasis in Bioactive Products at Universidade Paranaense (UNIPAR).

Discussion: The samples were subjected to phenotypic antimicrobial sensitivity tests and phenotypic testing for detecting ESBL-producing strains. Escherichia coli was identified and isolated from the cloacal sample. Phenotypic tests for antimicrobial sensitivity, detected resistance to the following antimicrobials: ceftriaxone, ceftiofur, cefotaxime, cefepime, ampicillin, amoxicillin, amoxicillin + clavulanate, and tetracycline. The phenotypic test for detecting ESBL-producing strains was positive. The findings in this study had no relation with the clinical symptoms presented by the parrot. However, in the samples collected, it was possible to detect the presence of ESBL-producing Escherichia coli, indicating that this parrot had strains in its cloacal microbiota that were either multidrug-resistant or at a subclinical stage of an infection. This knowledge is important, since the presence of this bacteria in a pet represents an important factor in the dissemination of multidrug-resistant strains into the environment, as well as being a source of contamination for both humans and other animals.
\end{abstract}

Keywords: antibiotics, birds, enterobacteria, gram-negative bacteria, health risk.

${ }^{1}$ Programa de Pós-graduação em Ciência Animal com Ênfase em Produtos Bioativos \& ${ }^{2}$ Curso de Medicina Veterinária, Universidade Paranaense (UNIPAR), Umuarama, PR, Brazil. CORRESPONDENCE: D.D. Gonçalves [danieladib@ prof.unipar.br - Tel.: +55 (44) 3621-2828]. Programa de Pósgraduação em Ciência Animal com Ênfase em Produtos Bioativos, UNIPAR. Praça Mascarenhas de Moraes n. 4282. Bairro Centro. CEP $87502-210$ Umuarama, PR, Brazil. 


\section{INTRODUCTION}

The indiscriminate use of antibiotics, both in humans and in animals, has contributed to the development of resistance of bacteria to antibiotics [6,11].

In humans, 30 to $35 \%$ of all cases of sepsis, more than $70 \%$ of urinary infections, and the most common and relevant intestinal infections are caused by bacteria of the family Enterobacteriaceae. Production of extended spectrum $\beta$-lactamases (ESBLs) is one of the main mechanisms by which Enterobacteriaceae develop resistance, thus reducing the available therapeutic options [5].

Several bird species such as the Brazilian blue-fronted-amazon parrot (Amazona aestiva), live with humans. This bird is known for its beautiful and colorful feathers as well as its capacity for learning vocabulary and imitating human speech. It is therefore, very popular as a pet [2].

Even though this species has been quite extensively studied in clinical terms, there are few studies related to bacterial infections, especially regarding ESBL resistance in these parrots. Thus, the purpose of this study was to detect ESBL-producing Enterobacteriaceae in isolates from a pet blue-fronted-amazon parrot.

\section{CASE}

A 16-year-old pet blue-fronted-amazon parrot (Amazona aestiva) weighing $0.445 \mathrm{~kg}$, from the city of Presidente Castelo Branco, Paraná, Brazil (Figure 1), was admitted into a specialized veterinary clinic in the city of Maringá. This parrot was presented with agitation and aggressive behavior. It was fed with sunflower seeds, its cage was small and unsanitary, especially in the feeding and drinking areas, which were heavily contaminated with feces. The parrot had been diagnosed with acute sinusitis approximately one year prior, with a history of treatment with tylosin, thuya (a herbal remedy popularly used for fowl pox), and a mineral-vitamin complex.

The clinical symptoms included dyspnea and bilateral increase of facial swelling, with emphasis on the presence of a mass in the perinasal region. A membranous red tissue not related to the nictitating membrane was observed in the lower left eyelid (Figure 1). In order to obtain a better clinical evaluation, the bird was anesthetized with an intramuscular injection of dextroketamine $50 \mathrm{mg} / \mathrm{kg}\left(\operatorname{KetaminS}+^{\mathrm{TM}}\right)^{1}$. Subsequently, physical examination, head radiographic examinations, and an attempt at sinus draining were performed. The radiographic examinations showed a decreased amount of air in the nasal sinuses.

For treatment, oral itraconazole and vitamin A were prescribed, and a dietary improvement prioritizing the offering of fruits and industrialized food for parrots was proposed.

Samples were collected from the cloaca and choanae by making rotating movements with compressed sterile swabs in the corresponding locations. All samples were kept in Amies transport medium with activated coal and forwarded under refrigeration to the Laboratory of Preventive Veterinary Medicine and Public Health in the Post-Graduation Program in Animal Sciences with Emphasis in Bioactive Products at Universidade Paranaense (UNIPAR).

At the laboratory, the swabs containing the samples were placed in tubes containing $3.0 \mathrm{~mL}$ of Brain Heart Infusion (BHI) medium, and incubated at $37^{\circ} \mathrm{C}$ for $24 \mathrm{~h}$. After incubation, the cultures obtained were sown by striation in plates containing MacConkey agar with $10 \mu / \mathrm{mL}$ cefotaxime, and MacConkey agar with $50 \mu \mathrm{g} / \mathrm{mL}$ nalidixic acid. These plates were incubated at $37^{\circ} \mathrm{C}$ for $24 \mathrm{~h}$ in order to isolate the colonies resistant to cephalosporines and fluoroquinolones. The isolated colonies were preserved in $\mathrm{BHI}$ medium and then were stored in $80 \%$ glycerol at $-20^{\circ} \mathrm{C}$ for preservation [8].

The biochemical identification of the bacteria belonging to the Enterobacteriaceae family was made using the "Kit para Enterobactérias" Enterobacteria $\mathrm{Kit}^{2}$, according to the manufacturer's instructions [8].

In order to determine the bacterial resistance profile, the agar diffusion disk method was used, according to the recommendations by the Clinical and Laboratory Standards Institute [3]. The tested discs were the following: gentamicin, ciprofloxacin, ceftazidime, sulfazotrim, amikacin, aztreonam, chloramphenicol , ampicillin, tobramycin, cefoxitin, ceftriaxone, cefepime , cefotaxime, tetracycline, amoxicillin, amoxicillin + clavulanate, imipenem, meropenem, ertapenem, norfloxacin, nalidixic acid, enrofloxacin, and ceftiofur.

The double disc synergy test was performed, with the discs containing cefotaxime, ceftazidime, ceftriaxone, and aztreonam distributed at a $20-\mathrm{mm}$ distance from another disc containing amoxicillin + clavulanate $(20 / 10 \mu \mathrm{g})$. Any increase or distortion in the inhibition zone of any of the antibiotics towards the amoxicillin + clavulanate disc was considered suggestive of ESBL production [1]. 
Bacterial growth in BHI was observed in all samples collected. However, when transferring them to MacConkey agar with cefotaxime, only the cloaca sample presented bacterial growth, allowing for isolation and identification of Escherichia coli.

In the phenotypic tests for the sensitivity to antimicrobials, resistance to the following antimicrobials was observed: ceftriaxone, ceftiofur, cefotaxime, cefepime, ampicillin, amoxicillin, amoxicillin + clavulanate, and tetracycline (Figure 2). The phenotypic test for detecting ESBL-producing strains was positive (Figure 3).

\section{DISCUSSION}

The presence of multidrug-resistant bacteria in animals is not always related to the incorrect use of antibiotics or to mutation events, due to selective pressures that make bacteria resistant. In many cases, animals may have acquired multidrug-resistant strains from the environment itself [11]. Given that the strain in this study was isolated from a pet bird, it cannot be ruled out that the bird may have acquired the strain directly from its care givers, because different studies have isolated multidrug-resistant $E$. coli strains in healthy humans [10].

Despite these assumptions, the relevance of this study lies in the isolation of an ESBL-producing strain from a pet, which can be a source of contamination and dissemination of such bacteria. ESBL-producing strains are particularly important since they usually present cross-resistance to quinolones and trimethoprim + sulfamethoxazole [7]. Such multidrug-resistant profiles reduce the therapeutic options, making it difficult to treat infec-

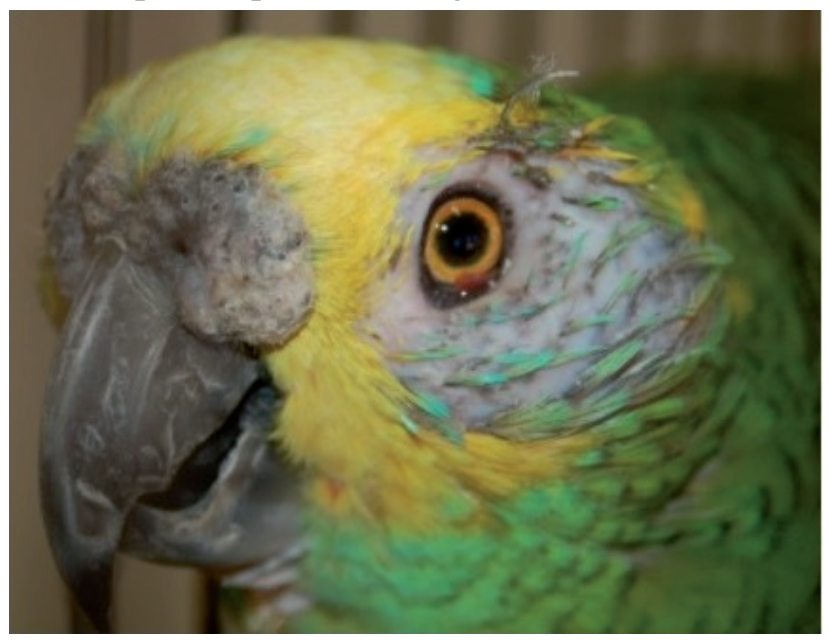

Figure 1. Pet blue-fronted-amazon parrot (Amazona aestiva) from the city of Presidente Castelo Branco, Paraná, Brazil. A bilateral increase of facial swelling, and the presence of a mass in the peri-nasal region can be observed. In the lower left eyelid, a membranous red tissue not related to the nictitating membrane was observed.

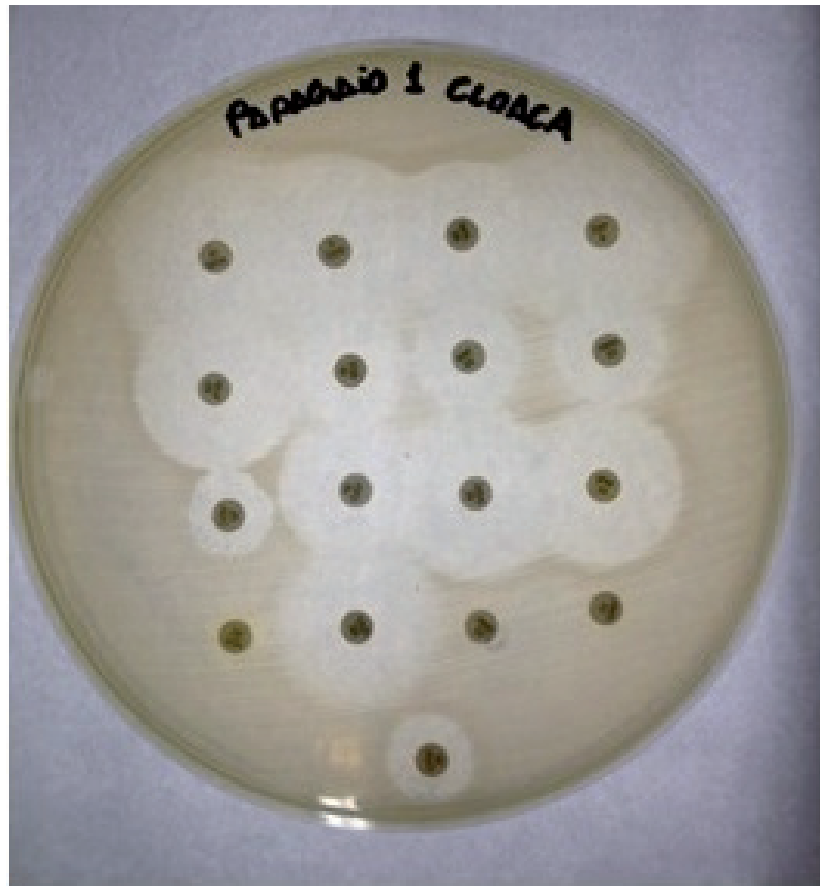

Figure 2. Resistance to ceftriaxone, ceftiofur, cefotaxime, cefepime, ampiciliin, amoxicillin, amoxicillin + clavulanate, and tetracycline antimicrobials in the phenotypic test to check the sensitivity to antimicrobials from a sterile swab collected from the cloaca region of a pet blue-fronted-amazon parrot (Amazona aestiva).

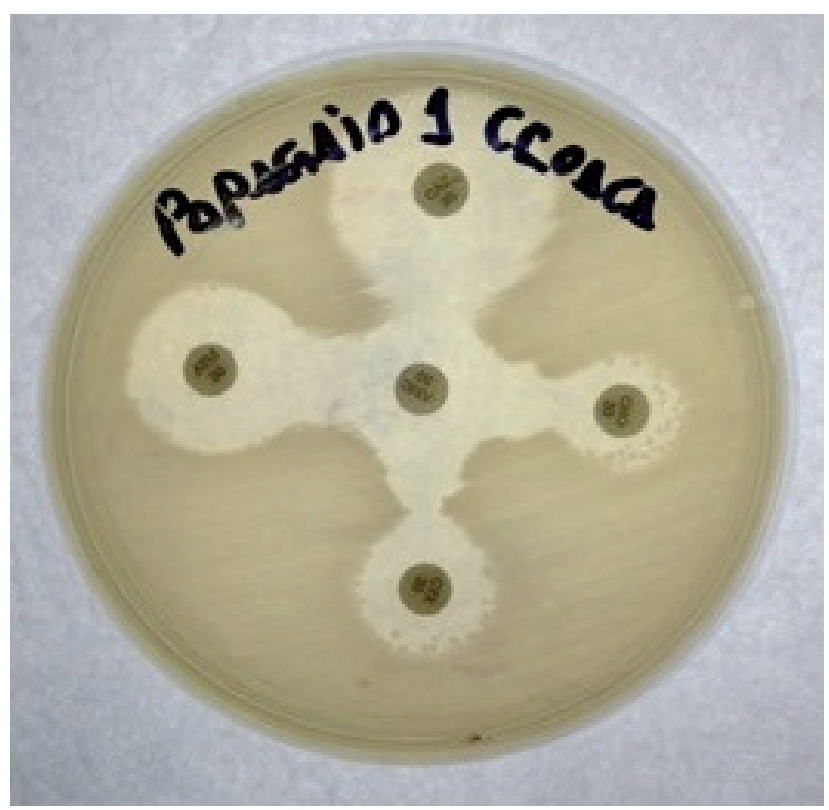

Figure 3. Phenotypic test for detecting positive ESBL-producing strains, presenting an increase or distortion in the inhibition zone of one of the antibiotics (Cefotaxime, Ceftazidime, Ceftriaxone, and Aztreonam) towards the amoxicillin + clavulanate disk from the sterile swab in the cloaca region of a pet blue-fronted-amazon parrot (Amazona aestiva).

tions in both people and animals. The early identification of ESBL production allows for a greater control of the dissemination of the bacteria to the community and the environment, as well speeds up appropriate treatment [7].

Regarding the isolation of resistant bacteria in birds, Horn et al. [4], isolated 61 bacterial strains from 42 cloacal and 9 necropsy swabs from canaries 
(Serinus canarius) in the city of Fortaleza, in the State of Ceará, Brazil. The species found were Escherichia coli, Klebsiella spp., Enterobacter spp., Pantoea agglomerans, Serratia spp., and Proteus mirabilis, with E. coli being the most prevalent one, with a total of 25 isolations. Regarding sensitivity to antimicrobials, the strains presented higher resistance to sulfonamides $(55.70 \%)$, ampicillin $(54.10 \%)$, and tetracycline $(39.30 \%)$. Additionally, the total number of strains resistant to multiple drugs was $55.70 \%$, concluding that the birds analyzed, as well as being colonized by enterobacteria, also presented strains with a high level of resistance to some antimicrobial classes.

Similar results were obtained by Santos et al. [9], who identified a greater prevalence of $E$. coli (70.50\%), Staphylococcus aureus (49.00\%), and Streptococcus spp. (25.40\%) when analyzing samples from cloacal swabs of 51 captive cracidae birds from 10 different species in the State of Rio Grande do Sul, Brazil. With respect to sensitivity, all 93 isolated strains were sensitive to only imipenem, and it was observed that the birds studied presented multidrug-resistant bacteria from several genera and species in their cloacal microbiota, which presented different resistance mechanisms.

The findings in this study had no relation with the clinical symptoms presented by the parrot. However, in the samples collected, it was possible to detect the presence of ESBL-producing Escherichia coli, indicating that this parrot had strains in its cloacal microbiota that were either multidrug-resistant or at a subclinical stage of an infection. Such knowledge is important, since the presence of this bacteria in a pet represents an important factor in the dissemination of multidrug-resistant strains into the environment, as well as being a source of contamination for both humans and other animals, thus being considered a unique health risk.

\section{MANUFACTURERS}

${ }^{1}$ Laboratorio Cristália. Itapira, SP, Brazil.

${ }^{2}$ NewProv. Pinhais, PR, Brazil.

Declaration of interest. The authors report no conflicts of interest. The authors alone are responsible for the content and writing of the paper.

Acknowledgements. The autors would like to thank Universidade Paranaense (UNIPAR) for funding this study, and CAPES, for the PROSUP grant.

\section{REFERENCES}

1 Brun-Buisson C., Legrand P., Philippon A., Montravers F., Ansquer M. \& Duval J. 1987. Transferable enzymatic resistance to third-generation cephalosporins during nosocomial outbreak of multi-resistant Klebsiella pneumoniae. Lancet. 8(2): 302-306.

2 Christofoletti M.D. 2014. Reprodução de papagaio-verdadeiro (Amazona aestiva) em cativeiro: perfil anual de esteróides sexuais e ensaio de estímulo hormonal exógeno. 59p. Jaboticabal, SP. Tese (Doutorado em Medicina Veterinária) Universidade Estadual Paulista, Faculdade de Ciências Agrárias e Veterinárias, Universidade Estadual Paulista.

3 Clinical and Laboratory Standards Institute (CLSI). 2013. Performance Standards for Antimicrobial Susceptibility Testing: Twenty-third Informational Supplement M100-S23. Wayne: CLSI, 199p.

4 Horn R.V., Cardoso W.M., Lopes E.S., Teixeira R.S.C., Albuquerque A.H., Silva R.C.R., Machado D.N. \& Bezerra W.G.A. 2015. Identification and antimicrobial resistance of members from the Enterobacteriaceae family isolated from canaries (Serinus canaria). Pesquisa Veterinária Brasileira. 35(6): 552-556.

5 Mana M., Bonassi N., Romanelli S., Svidzinsk T.I.E. \& Lemes R.M.L. 2014. Prevalência de Klebsiella spp. ESBL isolada em hospital Escola do sul de Minas Gerais. Revista da Universidade Vale do Rio Verde. 12(2): 497-506.

6 Oliveira M.R.M. \& Medeiros M. 2015. Agentes causadores de mastite e resistência bacteriana. Revista Científica de Medicina Veterinária. 2(1): 45-60.

7 Picozzi S.C.M., Casellato S., Rossini M., Paola G., Tejada M., Costa E. \& Carmignani L. 2014. Extended-spectrum beta-lactamase-positive Escherichia coli causing complicated upper urinary tract infection: Urologist should act in time. Urology Annals. 6(2): 107-112.

8 Quinn P.J., Markey B.K., Cater M.E., Donnely W.J. \& Leonar F.C. 2005. Microbiologia Veterinária e Doenças Infecciosas. Porto Alegre: Artmed, 512p. 
9 Santos H.F., Flôres M.L., Lara V.M., Silva M.S., Battisti L. \& Lovato L.T. 2010. Microbiota cloacal aeróbia de cracídeos cativos no Rio Grande do Sul e sua susceptibilidade a antimicrobianos. Pesquisa Veterinária Brasileira. 30(12): 1077-1082.

10 Sidjabat H. \& Paterson D.L. 2015. Multidrug-resistant Escherichia coli in Asia: epidemiology and management. Expert review of anti-infective therapy. 13(5): 575-591.

11 World Health Organization (WHO). 2016. Regional Office for the Western Pacific. Antimicrobial resistance in the Western Pacific Region: a review of surveillance and health systems response. [Fonte:<http://apps.who.int/iris/bitstre am/10665/208222/1/9789290617013_eng.pdf. >]. [Accessed online in December 2016]. 